Central Washington University

ScholarWorks@CWU

All Faculty Scholarship for the College of the Sciences

$10-22-2019$

Magnetocaloric effect near room temperature in quintenary and sextenary Heusler alloys

Benjamin D. White

R. I. Barabash

O. M. Barabash

I. Jeon

M. B. Maple

Follow this and additional works at: https://digitalcommons.cwu.edu/cotsfac

Part of the Engineering Physics Commons, Metallurgy Commons, and the Sustainability Commons 


\title{
Magnetocaloric effect near room temperature in quintenary and sextenary Heusler alloys 두
}

\author{
Cite as: J. Appl. Phys. 126, 165101 (2019); doi: 10.1063/1.5120819 \\ Submitted: 21 July 2019 . Accepted: 2 October 2019. \\ Published Online: 22 October 2019
}

B. D. White, ${ }^{\text {1,a) }}$ R. I. Barabash, ${ }^{2}$ (D) O. M. Barabash, ${ }^{3}$ I. Jeon, ${ }^{4,5}$ and M. B. Maple ${ }^{4,5,6}$

\author{
AFFILIATIONS \\ ${ }^{1}$ Department of Physics, Central Washington University, Ellensburg, Washington 98926, USA \\ ${ }^{2}$ The University of Tennessee, Knoxville, Tennessee 37996, USA \\ ${ }^{3}$ Salk Institute for Biological Studies, 10010 N Torrey Pines Road, La Jolla, California 92037, USA \\ ${ }^{4}$ Materials Science and Engineering Program, University of California, San Diego, La Jolla, California 92093, USA \\ ${ }^{5}$ Center for Advanced Nanoscience, University of California, San Diego, La Jolla, California 92093, USA \\ ${ }^{6}$ Department of Physics, University of California, San Diego, La Jolla, California 92093, USA \\ a)benjamin.white@cwu.edu
}

\begin{abstract}
An inverse magnetocaloric effect is studied in $\mathrm{Ni}_{2} \mathrm{Mn}_{1+x} X_{1-x}$-type Heusler alloys. Principally known for their shape-memory properties, these alloys also exhibit significant entropy and temperature changes ( $\Delta S$ and $\Delta T_{A d}$, respectively) under adiabatic conditions when a modest magnetic field is applied. We investigated the impact on magnetocaloric properties of introducing substantial chemical disorder on the $X$-site $(X=\mathrm{Si}, \mathrm{Ga}, \mathrm{In})$, of replacing $\mathrm{Ni}$ with nonmagnetic $\mathrm{Ag}$, and of replacing a small amount of $\mathrm{Mn}$ with Gd. While a reduction in $\Delta S$ is observed in the first two cases, we observe a significant enhancement of $\Delta S$ when a small amount of Gd is substituted for Mn. A thermodynamic analysis was conducted using magnetization and heat capacity data to estimate adiabatic temperature changes in the range of $\Delta T_{A d} \simeq-1$ to $-3 \mathrm{~K}$ for a $5 \mathrm{~T}$ magnetic field. Several alloys characterized in this study exhibit these respectable $\Delta T_{A d}$ values near room temperature, making them potentially viable candidates for magnetic refrigeration applications.
\end{abstract}

Published under license by AIP Publishing. https://doi.org/10.1063/1.5120819

\section{INTRODUCTION}

Modern high-efficiency heating, ventilation, air conditioning, and refrigeration (HVACR) devices consume a significant fraction of the total energy used in residential and commercial buildings. ${ }^{1,2}$ Since increasing the efficiency of HVACR devices would have an immediate, meaningful impact on reducing global $\mathrm{CO}_{2}$ emissions, significant effort has been invested in developing higher-efficiency alternatives to the traditional gas-compression technology. Magnetic refrigeration technology is one of the most promising candidates; ${ }^{1,3,4}$ prototypes have demonstrated significantly better efficiency than the best commercial refrigerators. ${ }^{2,5}$ Furthermore, magnetic refrigerators operate using a solid material as their "refrigerant" rather than ozone depleting chemicals or greenhouse gases.

Magnetic refrigeration relies upon magnetocaloric materials that warm or cool when moderate magnetic fields are applied under adiabatic conditions. The magnetocaloric effect is characterized by the adiabatic changes in entropy, $\Delta S$, and temperature,
$\Delta T_{A d}$. In addition to having large values for $\Delta S$ and $\Delta T_{A d}$, viable candidates for magnetic refrigeration applications have ferromagnetic transitions with little or no thermal hysteresis and a Curie temperature, $T_{C}$, near room temperature (or in the desired working temperature range of the device) that can be modified via chemical substitution. ${ }^{6,7}$ The largest magnetocaloric effects are observed in materials with first-order magnetostructural transitions in which entropic changes originate from both the lattice and spin degrees of freedom. ${ }^{4,8}$ The magnetocaloric effect in compounds containing Gd, especially a "giant" magnetocaloric effect observed in alloys based on $\mathrm{Gd}_{5} \mathrm{Ge}_{4}\left(\Delta S \sim-20\right.$ to $\left.-70 \mathrm{~J} \mathrm{~kg}^{-1} \mathrm{~K}^{-1}\right),{ }^{9}$ has received significant attention over the last 20 years. ${ }^{5-7,9-13}$ A "colossal" magnetocaloric effect has also been observed in the compound MnAs under applied pressure ${ }^{14}\left(\Delta S \sim-267 \mathrm{~J} \mathrm{~kg}^{-1} \mathrm{~K}^{-1}\right)$ and in related alloys at ambient pressure ${ }^{8}\left(\Delta S \sim-325 \mathrm{~J} \mathrm{~kg}^{-1} \mathrm{~K}^{-1}\right)$; unfortunately, the toxicity of As is an obvious impediment for using MnAs in commercial applications. Progress in the development of viable 
magnetic refrigerators awaits identifying and characterizing alloys that are inexpensive, environmentally friendly, and work in larger temperature intervals with higher efficiency. This objective cannot be met without discovering new high-performance magnetic refrigerant materials.

Heusler alloys based on $\mathrm{Ni}_{2} \mathrm{MnX}(X=\mathrm{Ga}, \mathrm{In}, \mathrm{Sn}$, and $\mathrm{Sb})$ contain nontoxic elements, have high mechanical strength and good oxidation resistance, are easy to fabricate, and undergo first-order magnetostructural phase transitions. ${ }^{15}$ These attributes match desired properties for candidate refrigerant materials, which have motivated experimental magnetocaloric effect studies on these alloys. $^{16,17}$ The magnetocaloric properties of alloys with off-stoichiometric compositions of the form $\mathrm{Ni}_{2} \mathrm{Mn}_{1+x} X_{1-x}$ have received particular attention; this includes alloys with $X=\mathrm{Sb},{ }^{18-20}$ $X=\mathrm{Sn},{ }^{21-31}$ and $X=$ In $^{15,20,24,25,32-43}$ Magnetocaloric effect studies have also been conducted on $\mathrm{Ni}_{2} \mathrm{MnGa}^{44}$ and off-stoichiometric alloys with $X=\mathrm{Ga} \cdot{ }^{19-21,26,32,45-51}$ Large "inverse" magnetocaloric effects have been observed in many of these alloys, meaning that $\Delta S>0$ and $\Delta T_{A d}<0$ when a magnetic field is applied adiabatically. ${ }^{15,18,21,27}$

Modern functional alloys should be multicomponent to provide balanced properties. The trend for new multicomponent alloys with high magnetocaloric properties is illustrated in recent studies. 2,28,40 Many chemical substitution studies on $\mathrm{Ni}_{2} \mathrm{Mn}_{1+x} X_{1-x}$-based alloys focus on systematically replacing $\mathrm{Ni}$ with nearby $3 d$ transition metal elements (e.g., Fe, ${ }^{45,48-50,52,53}$ Co, ${ }^{15,19,22,23,26-29,31,37,40,50,51,54,55}$ and $\mathrm{Cu}^{33,47,52,56}$ ). Even modest amounts of Co have been shown to double or triple $\Delta S$ values as seen in $\mathrm{Ni}_{50-x} \mathrm{Co}_{x} \mathrm{Mn}_{38} \mathrm{Sb}_{12}{ }^{19}$ and $\mathrm{Ni}_{47.5-x} \mathrm{Co}_{x} \mathrm{Mn}_{37.5} \mathrm{Sn}_{15}{ }^{26}$ There have also been efforts to replace $\mathrm{Mn}$ with $\mathrm{Cr}^{35}$ On the other hand, significantly less work has been reported in which variations in $X$ elements are considered; however, studies of the magnetocaloric effect in $\mathrm{Ni}_{50} \mathrm{Mn}_{35} \mathrm{In}_{14} X(X=\mathrm{Si}, \mathrm{Ge}, \mathrm{Al}, \mathrm{In})^{32}$ and $\mathrm{Ni}_{50} \mathrm{Mn}_{35} \mathrm{In}_{15-x} \mathrm{Sb}_{x}{ }^{20}$ have demonstrated that small compositional changes in $X$ can have a significant impact on $\Delta S$ values.

We studied the effect of chemical substitution on the magnetocaloric properties of several multicomponent $\mathrm{Ni}_{2} \mathrm{Mn}_{1+x} X_{1-x^{-}}$ based alloys. $^{57}$ The specific quintenary and sextenary alloy compositions studied are listed in Table I and were selected because their magnetocaloric effects occur near room temperature. We focused on the effects of three situations: (1) introducing a substantial chemical disorder on the $X$-site $(X=\mathrm{Si}, \mathrm{Ga}$, and In), (2) replacing $\mathrm{Ni}$ with nonmagnetic $\mathrm{Ag}$, and (3) replacing $\mathrm{Mn}$ with

TABLE I. List of the alloy compositions prepared in this study and the sample number we use to refer to each composition in the figures and text. More information about the alloy compositions can be found in Ref. 57 .

\begin{tabular}{lc}
\hline \hline Sample number & Alloy composition \\
\hline 1 & $\mathrm{Ni}_{50} \mathrm{Mn}_{35} \mathrm{In}_{6} \mathrm{Ga}_{6} \mathrm{Si}_{3}$ \\
2 & $\mathrm{Ni}_{45} \mathrm{Ag}_{5} \mathrm{Mn}_{35} \mathrm{In}_{12} \mathrm{Si}_{3}$ \\
3 & $\mathrm{Ni}_{45} \mathrm{Mn}_{40} \mathrm{In}_{6} \mathrm{Ga}_{6} \mathrm{Si}_{3}$ \\
4 & $\mathrm{Ni}_{50} \mathrm{Mn}_{35} \mathrm{In}_{5.75} \mathrm{Ga}_{5.75} \mathrm{Si}_{3} \mathrm{Ge}_{0.5}$ \\
5 & $\mathrm{Ni}_{50} \mathrm{Mn}_{33.5} \mathrm{In}_{6} \mathrm{Gd}_{1.5} \mathrm{Ga}_{6} \mathrm{Si}_{3}$ \\
6 & $\mathrm{Ni}_{45} \mathrm{Ag}_{5} \mathrm{Mn}_{35} \mathrm{In}_{6} \mathrm{Ga}_{6} \mathrm{Si}_{3}$ \\
\hline \hline
\end{tabular}

small amounts of Gd. We report $\Delta S$ and $\Delta T_{A d}$ results that were obtained using measurements of heat capacity and magnetization. Estimates of $\Delta S$ values in the range of $1.5-9.5 \mathrm{~J} \mathrm{~kg}^{-1} \mathrm{~K}^{-1}$ were obtained using these data; the positive sign of $\Delta S$ is consistent with an inverse magnetocaloric effect. Isothermal measurements of magnetization as a function of magnetic field were made on selected alloys in order to estimate values for $\Delta T_{A d}$. We obtained values of roughly $-1 \mathrm{~K}$ to $-3 \mathrm{~K}$. The largest values of $\Delta S$ and $\Delta T_{A d}$ were found in sample 5 with the composition $\mathrm{Ni}_{50} \mathrm{Mn}_{33.5} \mathrm{In}_{6} \mathrm{Gd}_{1.5} \mathrm{Ga}_{6} \mathrm{Si}_{3}$.

Our results indicate that introducing a strong chemical disorder on the $X$-site and replacing $\mathrm{Ni}$ with nonmagnetic Ag tend to reduce $\Delta S$ in $\mathrm{Ni}_{2} \mathrm{Mn}_{1+x} X_{1-x}$-based alloys. On the other hand, replacing Mn with a small amount of Gd resulted in a significant enhancement of $\Delta S$. Alloying small amounts of Gd into other magnetocaloric compounds may be an effective strategy for enhancing their properties as well.

\section{EXPERIMENT}

Polycrystalline samples of the multicomponent Heusler alloys $^{57}$ summarized in Table I were synthesized at ORNL via a conventional solid state reaction. The pure constituent elements were weighed in stoichiometric ratios to yield $100 \mathrm{~g}$ samples of the chosen alloy compositions. The initial materials were heated to the melting temperature over $12 \mathrm{~h}$ to avoid significant vaporization of elements with high vapor pressure before they could be incorporated into the melt. Heating was performed in an inert Ar atmosphere using a high-frequency induction furnace. The resulting boule was remelted in the induction furnace under an Ar atmosphere to obtain a homogeneous polycrystalline cylinder with a diameter of $2.54 \mathrm{~cm}$. These samples were subjected to a two-step annealing process under an $\mathrm{Ar}$ atmosphere in which they were heated at $1000{ }^{\circ} \mathrm{C}$ for $72 \mathrm{~h}$ and at $800{ }^{\circ} \mathrm{C}$ for $24 \mathrm{~h}$.

The crystal structures and phase purity of all alloys in this study were checked at room temperature by performing x-ray diffraction measurements using a PANalytical X'Pert Pro MPD $\theta-\theta$ goniometer with Mo radiation (diffraction patterns not shown). Structural phase transitions from a cubic phase above the transition temperature to an orthorhombic (sometimes it can be tetragonal or monoclinic) phase below the transition temperature are expected in these Heusler alloys. To confirm that our samples exhibit such structural transitions, which play a role in enhanced magnetocaloric effects, $\mathrm{x}$-ray diffraction measurements were made as a function of temperature; these measurements were conducted using a PANalytical X'Pert MPD $\theta-\theta$ goniometer and $\mathrm{Cu}$ radiation. As an example, representative $\mathrm{x}$-ray diffraction patterns for sample 1 are shown as a function of temperature in Fig. 1. The patterns were collected in a narrow range of angles surrounding the (220) doublet of sample 1's room-temperature tetragonal structure. The doublet disappears as the sample is heated through the structural transition into its cubic phase. The room-temperature tetragonal structure is completely recovered by cooling back through the transition as is seen in Fig. 1. Samples with structural transition temperatures below room temperature had cubic symmetry at room temperature, which was confirmed by our $\mathrm{x}$-ray analysis.

The magnetocaloric effect was characterized in our samples using a combination of specific heat, $C$, and magnetization, $M$, 


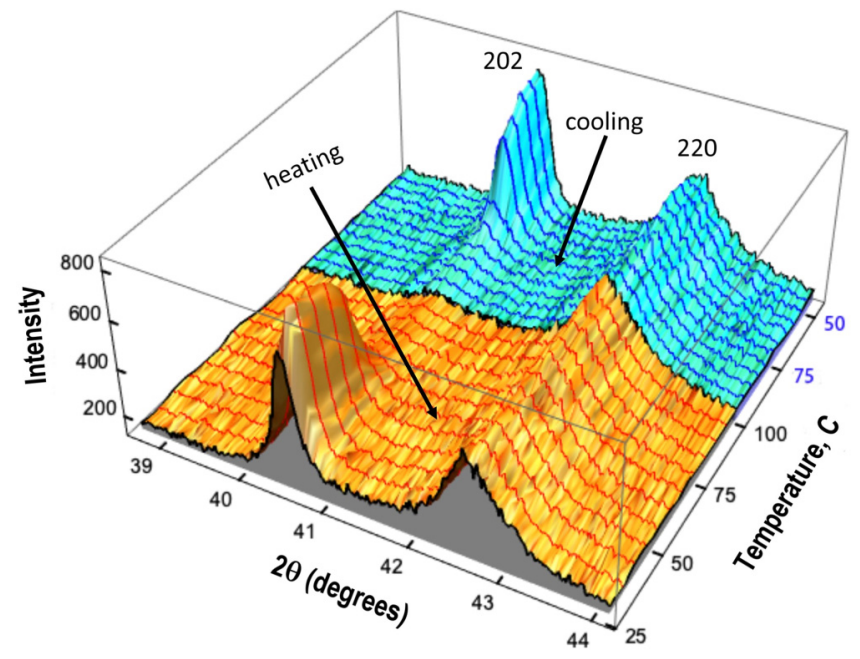

FIG. 1. X-ray diffraction patterns for sample $1\left(\mathrm{Ni}_{50} \mathrm{Mn}_{35} \mathrm{In}_{6} \mathrm{Ga}_{6} \mathrm{Si}_{3}\right)$ as a function of temperatures near the structural phase transition temperature. Diffraction patterns shown as orange lines were measured upon warming, while blue patterns were measured upon cooling as indicated in the figure. The patterns are arranged in sequential order from front to back.

measurements as functions of temperature, $T$, and magnetic field, $H$. Standard measurements of the specific heat using a conventional thermal-relaxation technique are incapable of accurately measuring $C(T)$ in the vicinity of a first-order phase transition at $T_{c}{ }^{58}$ significant deviations of the relaxation curve [i.e., temperature as a function of time $T(t)$ data] from exponential decay are caused by the latent heat of the sample. This issue generally leads to severe underestimates of $C(T)$ at the transition that prevent accurate calculations of the entropy associated with these features. We used an alternative technique in which a large heat pulse $\Delta T$ is applied starting from a base temperature $T_{0}<T_{c}$ such that the range $T_{0}+$ $\Delta T$ encompasses the entire feature associated with the first-order phase transition. ${ }^{58}$ From measured $T(t)$ data and other experimental parameters, we calculate $\Gamma(T)$,

$$
\Gamma(T)=\frac{d}{d t}\left[\ln \left(\left(T(t)-T_{0}\right) / \Delta T\right)\right]
$$

such that $C(T)$ can be obtained by calculating $C(T)=-K / \Gamma(T){ }^{58}$ $K$ is the thermal conductance of the Pt wires thermally connecting the calorimeter platform/sample to the bath at $T_{0}$ during the measurements. In practice, $K$ is calculated assuming $K=P / T$, where $P$ is the power dissipated by a thin-film heater mounted to the calorimeter platform; however, we corrected this value of $K$ for a modest linear temperature dependence of $K(T)$ in this temperature range. ${ }^{59}$ Apiezon $\mathrm{H}$ grease was used to mechanically and thermally couple samples to the calorimeter platform. Measurements of the specific heat of the grease were performed using a standard thermal relaxation technique prior to mounting the samples on the calorimeter puck. These addenda data were subtracted from calculated
$C(T)$ results to remove contributions associated with the grease and to obtain the specific heat of the samples. Measurements were performed in zero field and in applied magnetic fields of $H=1,2,3,4$, and $5 \mathrm{~T}$ using a PPMS DynaCool equipped with a superconducting magnet. A comparison between the conventional thermal-relaxation method and the single-pulse method is made in Fig. 2 for a representative sample.

The entropy variation with the applied magnetic field, $\Delta S(T)=S(T, H)-S(T, H=0 \mathrm{~T})$, was calculated by numerically integrating $C(T) / T$ data for each applied field with respect to temperature and subtracting the resulting entropy for zero field, $S(T, H=0 \mathrm{~T})$, from $S(T, H)$ data.

To obtain estimates for $\Delta T_{A d}$ on selected samples, we used a combination of $M(H)$ and $C(T)$ data. Invoking a well-known Maxwell relation and employing simple thermodynamic arguments, a differential adiabatic temperature change $d T_{A d}$, given a differential change in magnetic field $d H$, can be expressed,

$$
d T_{A d}=-\left(\frac{T}{C}\right)_{H}\left(\frac{\partial M}{\partial T}\right)_{H} d H,
$$

where the terms $(T / C)_{H}$ and $(\partial M / \partial T)_{H}$ are at fixed $H$. In practice, the latter term is obtained by taking numerical derivatives of distinct $M(H)$ data sets with respect to temperature at fixed $H$ values. The $M(H)$ measurements were made using a commercial SQUID magnetometer at temperatures in the vicinity of the first-order phase transition. Using these $M(H)$ and $C(T)$ measurements, the quantity $-(T / C)_{H}(\partial M / \partial T)_{H}$ can be calculated for as many magnetic fields as possible, and then $d T_{A d}$ [see Eq. (2)] is numerically integrated to obtain $\Delta T_{A d}$.

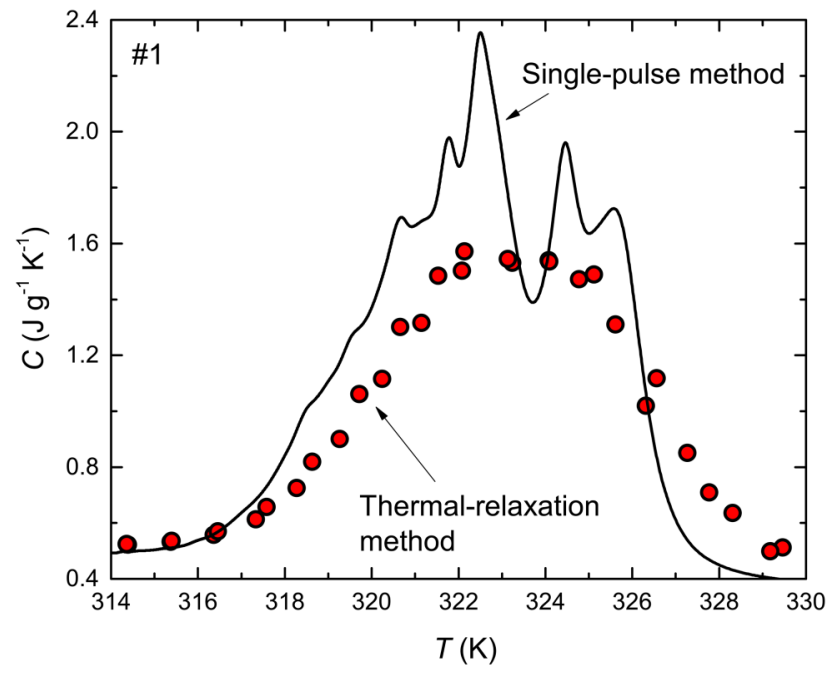

FIG. 2. Comparison of heat capacity measurements of sample 1 $\left(\mathrm{Ni}_{50} \mathrm{Mn}_{35} \mathrm{In}_{6} \mathrm{Ga}_{6} \mathrm{Si}_{3}\right)$ as a function of temperature using the single-pulse method (black curve) and the thermal-relaxation method (filled red circles). These methods are described in the text. 


\section{RESULTS AND DISCUSSION}

We report the results of measurements on six different quintenary and sextenary Heusler alloy compositions. For convenience, we refer to each composition by a number throughout the paper (see Table I). A comparison between our alloys and the stoichiometric Heusler compound $\mathrm{Ni}_{2} \mathrm{MnGa}\left(\mathrm{Ni}_{50} \mathrm{Mn}_{25} \mathrm{Ga}_{25}\right)$ reveals that our samples have nearly stoichiometric amounts of $\mathrm{Ni}$ (the exceptions are samples 2, 3, and 6 where we replaced some $\mathrm{Ni}$ with $\mathrm{Ag}$ or $\mathrm{Mn}$ ), excess $\mathrm{Mn}$, and varying amounts of $X=\mathrm{Ga}$, In, $\mathrm{Si}$, and Ge. These alloy compositions were chosen in order to study three chemical substitution effects: (1) introducing substantial chemical disorder on the $X$-site ( $X=\mathrm{Si}, \mathrm{Ga}$, and In), (2) replacing $\mathrm{Ni}$ with nonmagnetic $\mathrm{Ag}$, and (3) replacing $\mathrm{Mn}$ with small amounts of Gd.
Measurements of specific heat in magnetic fields of up to $5 \mathrm{~T}$ are shown in Fig. 3. These measurements were conducted using the single-pulse method described in the section on Experiment. In all cases, the prominent peaks associated with the phase transitions shift monotonically to lower temperature with increasing magnetic field. This same response was observed in related alloys $\mathrm{Ni}_{45} \mathrm{Co}_{5} \mathrm{Mn}_{38} \mathrm{Sb}_{12},{ }^{19} \mathrm{Ni}_{49} \mathrm{CuMn}_{34} \mathrm{In}_{16},{ }^{33}$ and $\mathrm{Ni}_{50} \mathrm{Mn}_{33.32} \mathrm{Cr}_{0.68} \mathrm{In}_{16} \cdot{ }^{35} \mathrm{~A}$ single, dominant peak is observed in samples 2, 3, and 5, while samples 1, 4, and 6 appear to exhibit at least two distinct peaks. The first-order martensitic-austenite structural transition and ferromagnetic transitions typically occur in close proximity to one another, but they can be separated in $\mathrm{Ni}_{2} \mathrm{Mn}_{1+x} X_{1-x}$-based alloys. ${ }^{21,33,35}$ As is noted in Ref. 21, maximized magnetocaloric effects are generally observed when these


FIG. 3. Heat capacity as a function of temperature, measured in applied magnetic fields of $H=0,1,2,3,4$, and $5 \mathrm{~T}$, for (a) sample $1\left(\mathrm{Ni}_{50} \mathrm{Mn}_{35} \mathrm{In}_{6} \mathrm{Ga}_{6} \mathrm{Si}_{3}\right)$, (b) sample $2\left(\mathrm{Ni}_{45} \mathrm{Ag}_{5} \mathrm{Mn}_{35} \mathrm{In}_{12} \mathrm{Si}_{3}\right)$, (c) sample $3\left(\mathrm{Ni}_{45} \mathrm{Mn}_{40} \mathrm{In}_{6} \mathrm{Ga}_{6} \mathrm{Si}_{3}\right)$, (d) sample $4\left(\mathrm{Ni}_{50} \mathrm{Mn}_{35} \mathrm{In}_{5.75} \mathrm{Ga}_{5.75} \mathrm{Si}_{3} \mathrm{Ge}_{0.5}\right)$, (e) sample $5\left(\mathrm{Ni}_{50} \mathrm{Mn}_{33.5} \mathrm{In}_{6} \mathrm{Gd}_{1.5} \mathrm{Ga}_{6} \mathrm{Si}_{3}\right)$, and (f) sample 6 $\left(\mathrm{Ni}_{45} \mathrm{Ag}_{5} \mathrm{Mn}_{35} \mathrm{In}_{6} \mathrm{Ga}_{6} \mathrm{Si}_{3}\right)$. Distinct curves are data measured in different applied magnetic fields. A large feature (or features for samples 1,4 , and 6$)$ are associated with the ferromagnetic and martensitic-austenite structural phase transitions. These phase transitions are suppressed to lower temperature by applied magnetic fields. Insets in panels (b) and ( $f$ ) highlight the more subtle field-driven shift of the phase transitions in these samples. 
two transitions are very close to one another. In sample 4, two large peaks centered near $308 \mathrm{~K}$ and $332 \mathrm{~K}$ and a modest humplike feature near $314 \mathrm{~K}$ are observed. Chemical inhomogeneity in this complex alloy has likely resulted in some phase segregation between two phases with first-order transitions near $308 \mathrm{~K}$ and $332 \mathrm{~K}$, respectively. In this study, we focus on the magnetocaloric effect associated with the dominant phase with its transition temperature near $308 \mathrm{~K}$. The applied magnetic field appears to have the most significant impact on the specific heat of sample 5 , suggesting that this alloy composition should have the largest $\Delta S$ value.

The change in entropy due to the application of the magnetic field was estimated using our specific heat data. The entropy at each magnetic field was calculated as a function of temperature by integrating $C / T$ with respect to temperature. We calculated the entropy using data from measurements in applied fields of $H=0$ and $5 \mathrm{~T}$ and the change in entropy was calculated, $\Delta S=S(T, H=5 \mathrm{~T})-S(T, H=0 \mathrm{~T})$. Results for $\Delta S$ are plotted in Fig. 4 for all six alloys. Sample 5 clearly has the largest $\Delta S$ value of roughly $9.5 \mathrm{~J} \mathrm{~kg}^{-1} \mathrm{~K}^{-1}$. Samples 1 and 4 have comparable $\Delta S$ results $\left(3.8 \mathrm{~J} \mathrm{~kg}^{-1} \mathrm{~K}^{-1}\right.$ and $3.3 \mathrm{~J} \mathrm{~kg}^{-1} \mathrm{~K}^{-1}$, respectively). We note that sample 4 has a smaller second $\Delta S$ feature associated with the higher-temperature transition observed in heat capacity. Samples 2 and 6 exhibit relatively small, broad entropy changes, while $\Delta S$ for sample 3 goes through a peak centered near $270 \mathrm{~K}$ before decreasing to a local minimum near $283 \mathrm{~K}$ and increasing thereafter with increasing temperature. This behavior is similar to the $\Delta S$ vs $T$ curves reported for $\mathrm{Ni}_{49} \mathrm{CuMn}_{34} \mathrm{In}_{16},{ }^{33} \mathrm{Ni}_{50} \mathrm{Mn}_{33.32} \mathrm{Cr}_{0.68} \operatorname{In}_{16},{ }^{35}$ $\mathrm{Ni}_{50} \mathrm{Mn}_{37} \mathrm{Sn}_{13},{ }^{21} \quad \mathrm{Ni}_{49.9} \mathrm{Mn}_{35.2} \mathrm{In}_{14.9},{ }^{20} \mathrm{Ni}_{50} \mathrm{Mn}_{34} \mathrm{Sn}_{8} \mathrm{In}_{8},{ }^{24}$ and $\mathrm{Ni}_{48.5-x} \mathrm{Co}_{x} \mathrm{Mn}_{37} \mathrm{Sn}_{14.5}$ with $x=0,1,2 .{ }^{27}$ The positive peak in $\Delta S$

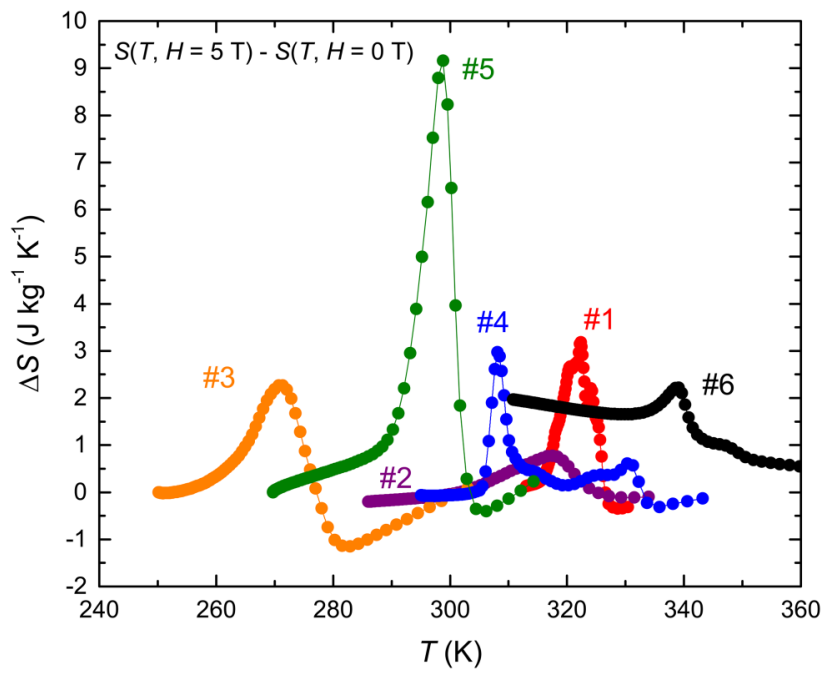

FIG. 4. Changes in entropy, $\Delta S$, between $0 \mathrm{~T}$ and $5 \mathrm{~T}$ are plotted as a function of temperature for samples $1\left(\mathrm{Ni}_{50} \mathrm{Mn}_{35} \mathrm{In}_{6} \mathrm{Ga}_{6} \mathrm{Si}_{3}\right), 2$ $\left(\mathrm{Ni}_{45} \mathrm{Ag}_{5} \mathrm{Mn}_{35} \mathrm{In}_{12} \mathrm{Si}_{3}\right), 3\left(\mathrm{Ni}_{45} \mathrm{Mn}_{40} \mathrm{In}_{6} \mathrm{Ga}_{6} \mathrm{Si}_{3}\right), 4\left(\mathrm{Ni}_{50} \mathrm{Mn}_{35} \mathrm{In}_{5.75} \mathrm{Ga}_{5.75} \mathrm{Si}_{3} \mathrm{Ge}_{0.5}\right)$, $5\left(\mathrm{Ni}_{50} \mathrm{Mn}_{33.5} \mathrm{In}_{6} \mathrm{Gd}_{1.5} \mathrm{Ga}_{6} \mathrm{Si}_{3}\right)$, and $6\left(\mathrm{Ni}_{45} \mathrm{Ag}_{5} \mathrm{Mn}_{35} \mathrm{In}_{6} \mathrm{Ga}_{6} \mathrm{Si}_{3}\right)$. Lines are guides to the eye. is a hallmark of the inverse magnetocaloric effect and is associated with the first-order martensitic transition; the smaller negative peak at higher temperature, which represents a conventional magnetocaloric effect, is associated with the ferromagnetic transition. ${ }^{21}$ Thus, there is a slight temperature separation between these two phase transitions in sample 3.

Our $\Delta S$ values can be compared with published results for alloys with comparable amounts of $\mathrm{Ni}$ and $\mathrm{Mn}$ which are listed in Table II. This comparison allows us to make some conclusions concerning several chemical substitution effects. (1) First, most of our $\Delta S$ values are about an order of magnitude smaller than the values listed in Table II. This is likely a consequence of the significant amount of the chemical disorder on the $X$ site in our quintenary and sextenary alloys, nearly all of which have three distinct elements occupying that position. This can be contrasted with the alloys listed in Table II in which there is generally a single element on the $X$ position (or two at most). Specifically, we can compare $\Delta S=3.8 \mathrm{~J} \mathrm{~kg}^{-1} \mathrm{~K}^{-1}$ for alloy $1\left(\mathrm{Ni}_{50} \mathrm{Mn}_{35} \mathrm{In}_{6} \mathrm{Ga}_{6} \mathrm{Si}_{3}\right)$ with $\Delta S=15 \mathrm{~J} \mathrm{~kg}^{-1} \mathrm{~K}^{-1}$ reported ${ }^{21}$ for $\mathrm{Ni}_{50} \mathrm{Mn}_{35} \mathrm{Sn}_{15}$. These alloys only differ in their $X$-site compositions. (2) Second, the alloys with the smallest $\Delta S$ values (samples 2 and 6) are those in which small amounts of $\mathrm{Ni}$ were replaced by nonmagnetic Ag. Previous studies in which a small amount of $\mathrm{Ni}$ has been replaced with magnetic Co or Fe have resulted in enhanced magnetocaloric properties. $^{19,26}$ The significant reduction of the magnetocaloric properties when a nonmagnetic element is introduced onto the $\mathrm{Ni}$ site is consistent with our expectations. (3) Third, our largest value of $\Delta S=9.5 \mathrm{~J} \mathrm{~kg}^{-1} \mathrm{~K}^{-1}$ for sample 5 is comparable with many of the published results summarized in Table II. A small amount of Mn was replaced by Gd in this alloy, apparently offsetting any reduction in the magnetocaloric response due

TABLE II. Published $\Delta S$ results for alloys with similar $\mathrm{Ni}$ and $\mathrm{Mn}$ compositions to those in this study (close to $\mathrm{Ni}_{50} \mathrm{Mn}_{35} X_{15}$ ). Results are displayed in order of decreasing $\Delta S$. Unless otherwise indicated, values of $\Delta S$ were obtained in $5 \mathrm{~T}$ magnetic fields.

\begin{tabular}{lcc}
\hline \hline Alloy composition & $\Delta S\left(\mathrm{~J} \mathrm{~kg}^{-1} \mathrm{~K}^{-1}\right)$ & Reference \\
\hline $\mathrm{Ni}_{49} \mathrm{CuMn}_{34} \mathrm{In}_{16}$ & $25.8($ at $4.5 \mathrm{~T})$ & 33 \\
$\mathrm{Ni}_{50} \mathrm{Mn}_{33.32} \mathrm{Cr}_{0.68} \mathrm{In}_{16}$ & 24.4 & 35 \\
$\mathrm{Ni}_{50.2} \mathrm{Mn}_{35.0} \mathrm{In}_{14.8}$ & $22.1($ at $2 \mathrm{~T})$ & 39 \\
$\mathrm{Ni}_{48.3} \mathrm{Mn}_{36.1} \mathrm{In}_{10.1} \mathrm{Sb}_{5.5}$ & 21.5 & 20 \\
$\mathrm{Ni}_{50} \mathrm{Mn}_{37} \mathrm{Sn}_{13}$ & 18 & 21 \\
$\mathrm{Ni}_{50} \mathrm{Mn}_{37} \mathrm{Sb}_{13}$ & 17.7 & 18 \\
$\mathrm{Ni}_{50} \mathrm{Mn}_{35} \mathrm{Sn}_{15}$ & 15 & 21 \\
$\mathrm{Ni}_{49.9} \mathrm{Mn}_{35.2} \mathrm{In}_{14.9}$ & 13.4 & 20 \\
$\mathrm{Ni}_{49.6} \mathrm{Mn}_{35.6} \mathrm{In}_{14.8}$ & $10.6($ at $2 \mathrm{~T})$ & 39 \\
$\mathrm{Ni}_{49.0} \mathrm{Mn}_{35.9} \mathrm{In}_{9.1} \mathrm{Sb}_{8.0}$ & 10.3 & 20 \\
$\mathrm{Ni}_{50} \mathrm{Mn}_{34} \mathrm{Sn}_{8} \mathrm{In}_{8}$ & 10.2 & 24 \\
$\mathrm{Ni}_{48.4} \mathrm{Mn}_{36.1} \mathrm{In}_{5.3} \mathrm{Sb}_{10.2}$ & 8.6 & 20 \\
$\mathrm{Ni}_{49.8} \mathrm{Mn}_{35.0} \mathrm{In}_{15.2}$ & $8.2($ at $2 \mathrm{~T})$ & 39 \\
$\mathrm{Ni}_{50} \mathrm{Mn}_{38} \mathrm{Sb}_{12}$ & 7 & 19 \\
$\mathrm{Ni}_{48.5} \mathrm{Mn}_{37} \mathrm{Sn}_{14.5}$ & $6.15($ at $1.5 \mathrm{~T})$ & 27 \\
$\mathrm{Ni}_{47.5} \mathrm{Mn}_{37.5} \mathrm{Sn}_{15}$ & $3($ at $1.5 \mathrm{~T})$ & 26 \\
$\mathrm{Ni}_{48} \mathrm{Mn}_{36} \mathrm{In}_{16}$ & $2.1($ at $1 \mathrm{~T})$ & 30 \\
\hline \hline
\end{tabular}


to the chemical disorder on the $X$-site. It is instructive to compare $\Delta S$ values for alloys $1\left(\mathrm{Ni}_{50} \mathrm{Mn}_{35} \mathrm{In}_{6} \mathrm{Ga}_{6} \mathrm{Si}_{3}\right)$ and 5 $\left(\mathrm{Ni}_{50} \mathrm{Mn}_{33.5} \mathrm{In}_{6} \mathrm{Gd}_{1.5} \mathrm{Ga}_{6} \mathrm{Si}_{3}\right)$ to see that $\mathrm{Gd}$ substitution significantly enhances $\Delta S$ from $3.8 \mathrm{~J} \mathrm{~kg}^{-1} \mathrm{~K}^{-1}$ to $9.5 \mathrm{~J} \mathrm{~kg}^{-1} \mathrm{~K}^{-1}$. Given the prevalence of $\mathrm{Gd}$-based compounds and alloys among the best magnetocaloric materials, this result is not surprising. While the expense and relative scarcity of Gd prevents widespread use of Gd-based compounds in commercial magnetocaloric devices, our result suggests that alloying small amounts of $\mathrm{Gd}$ into non-Gd-based compounds may be a suitable strategy for enhancing their magnetocaloric properties.

Based on the results summarized in Fig. 4, we chose to determine the adiabatic temperature changes, $\Delta T_{A d}$, for samples 1,4 , and 5. These samples exhibited the most promising $\Delta S$ values and have related alloy compositions. Sample 1 is $\mathrm{Ni}_{50} \mathrm{Mn}_{35} \mathrm{In}_{6} \mathrm{Ga}_{6} \mathrm{Si}_{3}$, while the other two are based on the same composition with a small amount of Gd replacing $\mathrm{Mn}$ in sample 5 and a small amount of $\mathrm{Ge}$ replacing In and $\mathrm{Ga}$ in sample 4.

Magnetization data for samples 1, 4, and 5 are displayed in Fig. 5 as a function of temperature. These data were measured in an applied field of $H=1 \mathrm{~T}$. A relatively sharp decrease in the magnetization with decreasing temperature is observed in each sample. This decrease is associated with the structural transition from the austenite phase at high temperature to a martensitic phase at low temperature. This first-order phase transition leads to a clear thermal hysteresis observed in all three samples (see insets in Fig. 5). These sharp features were also observed in the specific heat measurements displayed in Fig. 3. Substitution of small amounts of $\mathrm{Gd}$ and $\mathrm{Ge}$ into
$\mathrm{Ni}_{50} \mathrm{Mn}_{35} \mathrm{In}_{6} \mathrm{Ga}_{6} \mathrm{Si}_{3}$ clearly suppresses the magnetic and structural transition temperatures by comparable amounts. However, Ge substitution (sample 4) increases the thermal hysteresis width relative to sample 1 (see the right-hand inset of Fig. 5). The high-temperature transition at $330-335 \mathrm{~K}$ that was observed in heat capacity measurements is also observed in $M$ vs $T$ (see the right-hand inset of Fig. 5). When small amounts of Gd are introduced (sample 5), the magnetization increases substantially and the hysteresis width does not appear to change significantly relative to that of sample 1 .

Isothermal measurements of magnetization as a function of magnetic fields of up to $5 \mathrm{~T}$ were conducted in $0.2 \mathrm{~T}$ intervals at temperatures near the first-order structural transition; these temperatures were selected using the data displayed in Fig. 5. The $M$ vs $H$ data for samples 1,4 , and 5 are displayed in Fig. 6. Numerical derivatives $(\partial M(T, H) / \partial T)_{H}$ were evaluated at each magnetic field and plugged into Eq. (2). Using data for specific heat, $C$, Eq. (2) was integrated from 0 to $5 \mathrm{~T}$, providing us with an estimate for the adiabatic temperature change, $\Delta T_{A d}$. The results for samples 1,4 , and 5 are displayed in Fig. 7. The largest value is $\Delta T_{A d} \simeq-3 \mathrm{~K}$ for sample 5 , while samples 1 and 4 exhibit $\Delta T_{A d} \simeq-1.5 \mathrm{~K}$ and $\Delta T_{A d} \simeq-1 \mathrm{~K}$, respectively. We can compare our results with direct measurements of $\Delta T_{A d}$ that have been reported for several other $\mathrm{Ni}_{2} \mathrm{Mn}_{1+x} X_{1-x}$-type Heusler alloys $^{15,25,30,37-39,42,54}$ (summarized in Table III). Our largest result for $\Delta T_{A d}$ has the same order of magnitude as many of these other results shown in Table III; however, we note that many of the $\Delta T_{A d}$ values from the literature were obtained at lower magnetic fields than $5 \mathrm{~T}$ as is specified in the table.

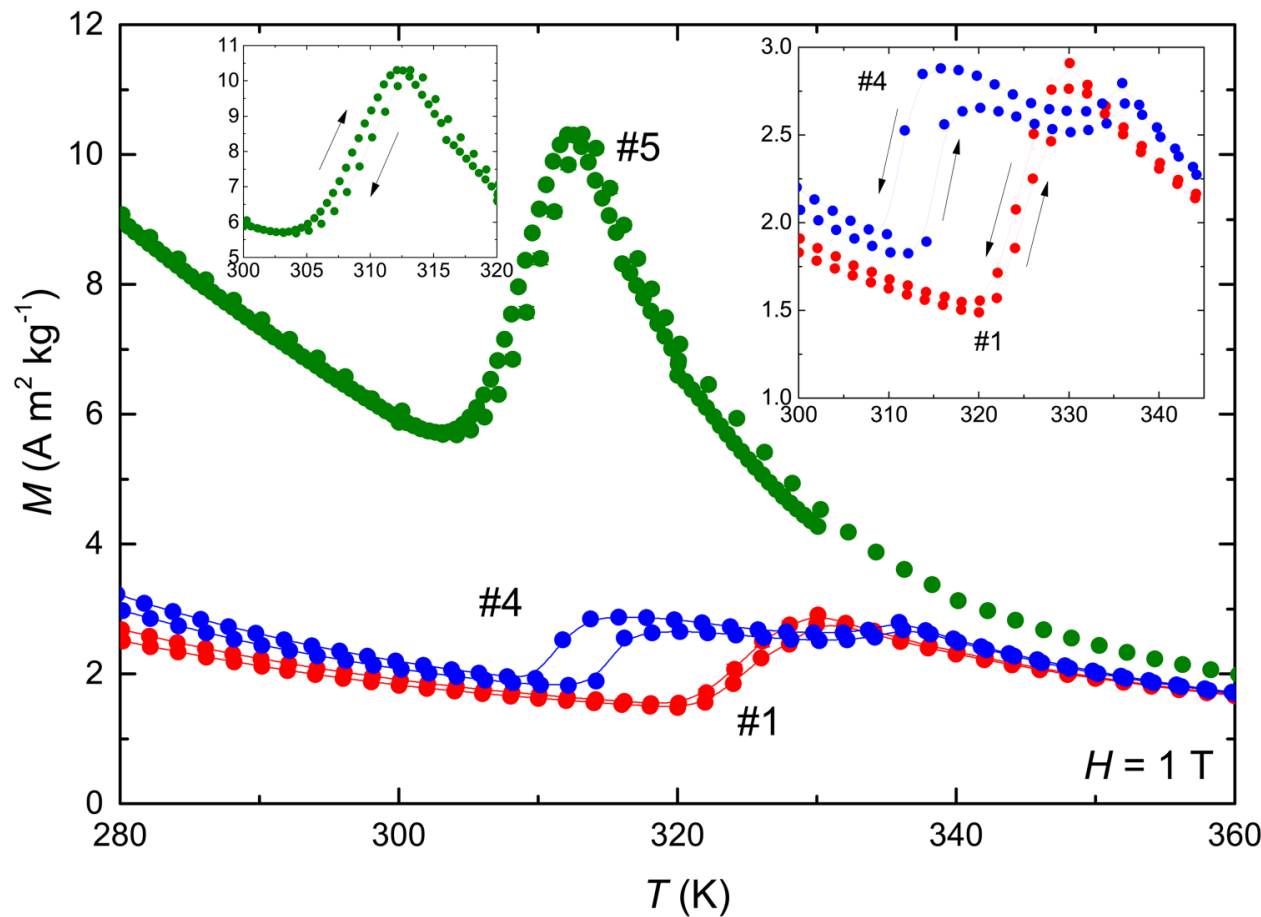

FIG. 5. Magnetization measured in an applied magnetic field of $H=1 \mathrm{~T}$ is plotted as a function of temperature for samples $1 \quad\left(\mathrm{Ni}_{50} \mathrm{Mn}_{35} \mathrm{In}_{6} \mathrm{Ga}_{6} \mathrm{Si}_{3}\right)$, $4\left(\mathrm{Ni}_{50} \mathrm{Mn}_{35} \mathrm{In}_{5.75} \mathrm{Ga}_{5.75} \mathrm{Si}_{3} \mathrm{Ge}_{0.5}\right)$, and $5\left(\mathrm{Ni}_{50} \mathrm{Mn}_{33.5} \mathrm{In}_{6} \mathrm{Gd}_{1.5} \mathrm{Ga}_{6} \mathrm{Si}_{3}\right)$. The lefthand inset shows the transition region in sample 5 , emphasizing the observed hysteresis. The right-hand inset shows the transition region for samples 1 and 4. A second feature at higher temperature, which indicates some phase segregation, can also be clearly observed for sample 4. Lines are guides to the eye. 

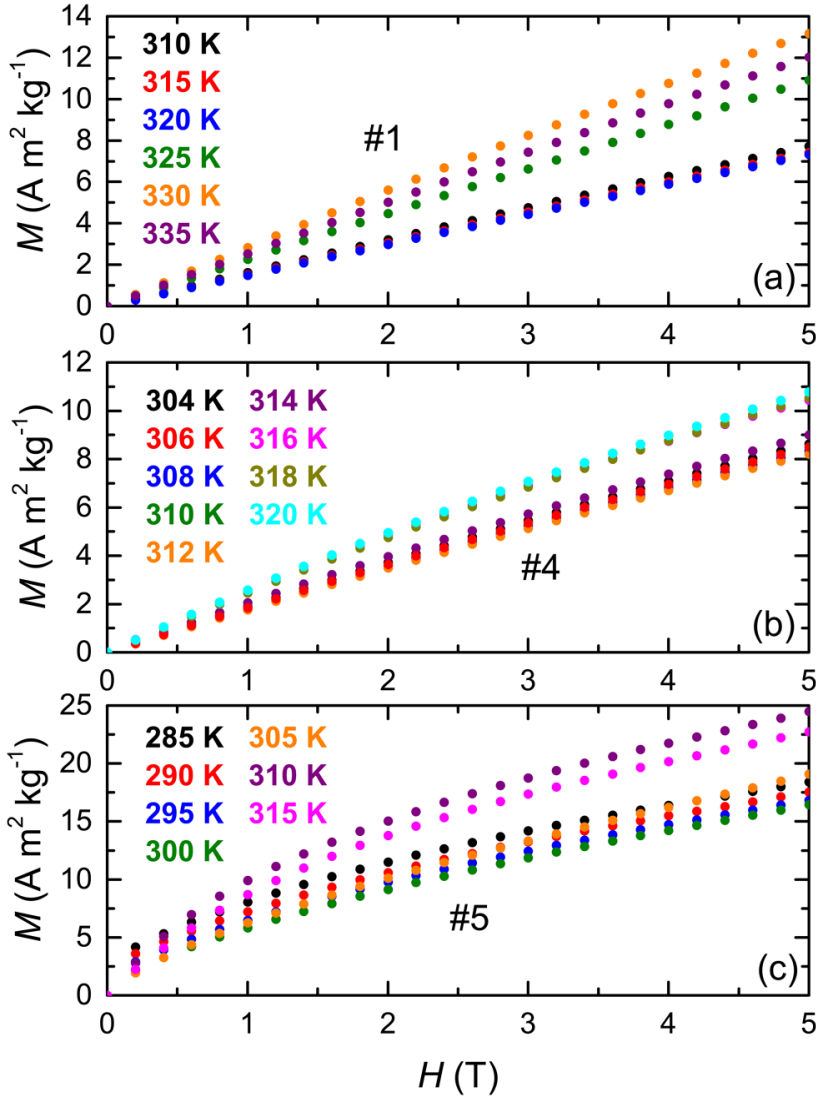

FIG. 6. Isothermal magnetization measured as a function of magnetic field, $H$, at temperatures near the first-order phase transition for (a) sample 1 $\left(\mathrm{Ni}_{50} \mathrm{Mn}_{35} \mathrm{In}_{6} \mathrm{Ga}_{6} \mathrm{Si}_{3}\right)$, (b) sample $4\left(\mathrm{Ni}_{50} \mathrm{Mn}_{35} \mathrm{In}_{5.75} \mathrm{Ga}_{5.75} \mathrm{Si}_{3} \mathrm{Ge}_{0.5}\right)$, and (c) sample $5\left(\mathrm{Ni}_{50} \mathrm{Mn}_{33.5} \mathrm{In}_{6} \mathrm{Gd}_{1.5} \mathrm{Ga}_{6} \mathrm{Si}_{3}\right)$. Measurements at each temperature are represented by filled circles of the color specified in the legend for each panel.

The most promising $\Delta T_{A d}$ result to date was obtained for $\mathrm{Ni}_{45.7} \mathrm{Mn}_{36.6} \mathrm{In}_{13.5} \mathrm{Co}_{4.2}$; this alloy undergoes a large adiabatic temperature change of $\Delta T_{A d} \simeq-8 \mathrm{~K}$ under an applied field of just $1.95 \mathrm{~T}$ within a few degrees of room temperature. ${ }^{54}$ Thermal hysteresis effects reduce the magnitude of $\Delta T_{A d}$ for subsequent magnetic field cycles, but $\Delta T_{A d}$ remains an impressive $-3 \mathrm{~K}$ on the second cycle.

Our negative $\Delta T_{A d}$ results are consistent with previous studies showing that $\mathrm{Ni}_{2} \mathrm{Mn}_{1+x} X_{1-x}$-type Heusler alloys exhibit an "inverse" magnetocaloric effect. ${ }^{15,18,21,27}$ Mesoscale coupling of the martensitic and magnetic domains allows changes in lattice parameters during the martensitic phase transition to modify the magnetic exchange interactions, driving this inverse effect. $^{21}$ An inverse magnetocaloric effect has also been reported for $\mathrm{Fe}_{0.49} \mathrm{Rh}_{0.51},{ }^{62} \mathrm{Mn}_{1.60} \mathrm{Cr}_{0.05} \mathrm{Sb}$, ${ }^{63}$ and $\mathrm{Mn}_{1.82} \mathrm{~V}_{0.18} \mathrm{~S}$. ${ }^{64}$ In these latter materials, a first-order phase transition from antiferromagnetic to ferromagnetic or ferrimagnetic states is driven by the applied field. Given the strong mixture of

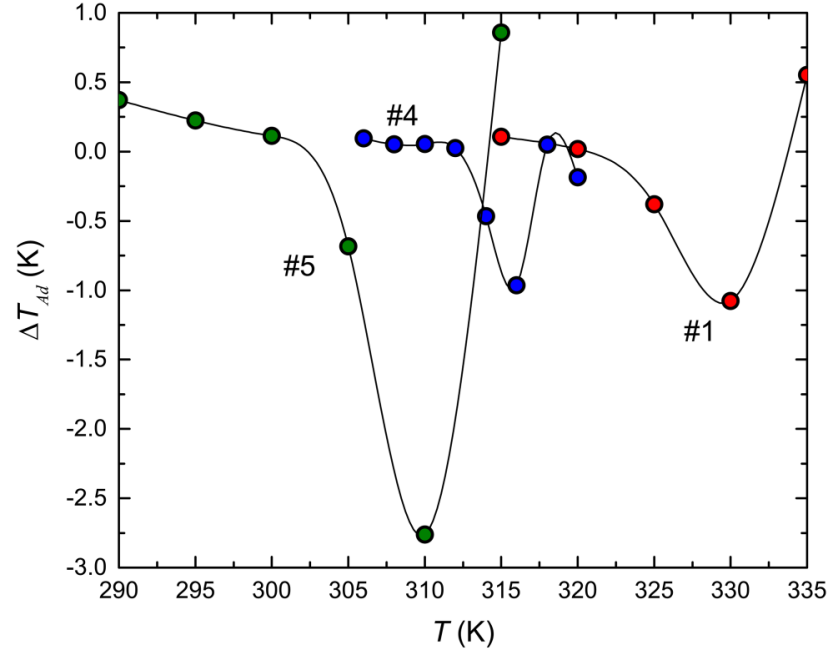

FIG. 7. The adiabatic temperature change, $\Delta T_{A d}$, is plotted as a function of temperature for samples $1\left(\mathrm{Ni}_{50} \mathrm{Mn}_{35} \mathrm{In}_{6} \mathrm{Ga}_{6} \mathrm{Si}_{3}\right), 4\left(\mathrm{Ni}_{50} \mathrm{Mn}_{35} \mathrm{In}_{5.75} \mathrm{Ga}_{5.75} \mathrm{Si}_{3} \mathrm{Ge}_{0.5}\right)$, and $5\left(\mathrm{Ni}_{50} \mathrm{Mn}_{33.5} \mathrm{In}_{6} \mathrm{Gd}_{1.5} \mathrm{Ga}_{6} \mathrm{Si}_{3}\right)$. $\Delta T_{A d}$ was calculated using a combination of magnetization and heat capacity measurements as described in the text. Lines are guides to the eye.

competing magnetic exchange interactions in these alloys, an applied magnetic field induces further spin disorder which increases the configurational entropy $(\Delta S>0)$ rather than reducing it. ${ }^{18}$

TABLE III. Published $\Delta T_{A d}$ results for related Heusler alloys. The results are organized by $\Delta T_{A d}$ value and include the magnetic field the results were obtained under. We have separated the results for inverse magnetocaloric effects $\left(\Delta T_{A d}<0 \mathrm{~K}\right)$ from results for conventional magnetocaloric effects $\left(\Delta T_{A d}>0 \mathrm{~K}\right)$.

\begin{tabular}{lccc}
\hline \hline Alloy composition & \multicolumn{3}{c}{$\begin{array}{c}\text { Temperature } \\
\text { of maximum } \\
\Delta T_{A d}(\mathrm{~K})\end{array}$} \\
\hline $\mathrm{Ni}_{45} \mathrm{Mn}_{45} \mathrm{In}_{10}$ & $-9($ at $20 \mathrm{~T})$ & 265 & Reference \\
$\mathrm{Ni}_{45.7} \mathrm{Mn}_{36.6} \mathrm{In}_{13.5} \mathrm{Co}_{4.2}$ & $-8($ at $1.95 \mathrm{~T})$ & 287 & 52 \\
$\mathrm{Ni}_{50} \mathrm{Mn}_{35} \mathrm{In}_{15}$ & $-7($ at $6 \mathrm{~T})$ & 250 & 38 \\
$\mathrm{Ni}_{49.8} \mathrm{Mn}_{35} \mathrm{In}_{15.2}$ & $-5.2($ at $2 \mathrm{~T})$ & 235 & 15 and 39 \\
$\mathrm{Ni}_{49.6} \mathrm{Mn}_{35.6} \mathrm{In}_{14.8}$ & $-5($ at $2 \mathrm{~T})$ & 274 & 39 \\
$\mathrm{Ni}_{45.25} \mathrm{Mn}_{41} \mathrm{In}_{13.75}$ & $-3.7($ at $2 \mathrm{~T})$ & 230 & 37 \\
$\mathrm{Ni}_{50.4} \mathrm{Mn}_{34.8} \mathrm{In}_{15.8}$ & $-3.6($ at $2 \mathrm{~T})$ & 192 & 15 \\
$\mathrm{Ni}_{40} \mathrm{Mn}_{50} \mathrm{Sn}_{10}$ & $-3.4($ at $5 \mathrm{~T})$ & 200 & 60 \\
$\mathrm{Ni}_{48.6} \mathrm{Mn}_{34.9} \mathrm{Sn}_{16.5}$ & $-2.6($ at $5 \mathrm{~T})$ & 149 & 25 \\
$\mathrm{Ni}_{43} \mathrm{Mn}_{37.75} \mathrm{In}_{12.25} \mathrm{Co}_{7}$ & $-2.4($ at $2 \mathrm{~T})$ & 310 & 37 \\
$\mathrm{Ni}_{43.25} \mathrm{Mn}_{45} \mathrm{In}_{11.75}$ & $-2.1($ at $2 \mathrm{~T})$ & 292 & 37 \\
$\mathrm{Ni}_{50.0} \mathrm{Mn}_{35.3} \mathrm{In}_{14.7}$ & $-2($ at $5 \mathrm{~T})$ & 296 & 25 \\
$\mathrm{Ni}_{51.3} \mathrm{Mn}_{32.9} \mathrm{In}_{15.8}$ & $-1.4($ at $3 \mathrm{~T})$ & 250 & 25 \\
$\mathrm{Ni}_{50.2} \mathrm{Mn}_{35.0} \mathrm{In}_{14.8}$ & $-1.1($ at $2 \mathrm{~T})$ & 301 & 39 \\
$\mathrm{Ni}_{55} \mathrm{Mn}_{20} \mathrm{Ga}_{25}$ & 2 (at $5 \mathrm{~T})$ & 310 & 61 \\
$\mathrm{Ni}_{48} \mathrm{Mn}_{36} \mathrm{In}_{16}$ & 1 (at $1 \mathrm{~T})$ & 316 & 30 \\
\hline \hline
\end{tabular}




\section{CONCLUSIONS}

We studied the impact of chemical substitution on the inverse magnetocaloric effect of multicomponent, $\mathrm{Ni}_{2} \mathrm{Mn}_{1+x} X_{1-x}$-based alloys; specifically, we studied the effects of (1) introducing a substantial chemical disorder on the $X$-site $(X=\mathrm{Si}, \mathrm{Ga}$, and In), (2) replacing a small amount of $\mathrm{Ni}$ with nonmagnetic $\mathrm{Ag}$, and (3) replacing a small amount of $\mathrm{Mn}$ with $\mathrm{Gd}$. Our results indicate that introducing a strong chemical disorder on the $X$-site and replacing $\mathrm{Ni}$ with nonmagnetic $\mathrm{Ag}$ both tend to reduce $\Delta S$ in $\mathrm{Ni}_{2} \mathrm{Mn}_{1+x} X_{1-x}$-based alloys. Chemical disorder also broadens the temperature region of the martensitic phase transition. So, while multicomponent alloys allow us to tune the transition temperature where magnetocaloric properties manifest, it appears to be at the cost of a reduction of the magnitude of $\Delta S$. On the other hand, replacing $\mathrm{Mn}$ with a small amount of $\mathrm{Gd}$ resulted in a significant enhancement of $\Delta S$, offsetting some of the reduction due to the chemical disorder. This result suggests that alloying small amounts of Gd into other non-Gd-based magnetocaloric compounds may be an effective strategy for enhancing their properties as well.

The largest $\Delta S$ values in $\mathrm{Ni}_{2} \mathrm{Mn}_{1+x} X_{1-x}$-type Heusler alloys are observed when the first-order martensitic transition coincides with the magnetic transition. It is not surprising, therefore, that our largest $\Delta S$ value was found in sample 5 where this coincidence between phase transitions was closest. In contrast, distinct features observed in specific heat and magnetization measurements of samples 1 and 4 indicated a significant separation between these phase transitions, which tends to reduce the magnitude of magnetocaloric properties.

The magnitude of $\Delta S$ is not the only metric that determines the viability of a magnetocaloric material for magnetic refrigeration applications. Perhaps even more relevant is the adiabatic temperature change $\Delta T_{A d}$, which we estimated for selected alloys using measurements of magnetization and specific heat. The largest adiabatic temperature change in response to an applied magnetic field of $5 \mathrm{~T}$ was observed to be $\Delta T_{A d} \sim-3 \mathrm{~K}$ in alloy 5 $\left(\mathrm{Ni}_{50} \mathrm{Mn}_{33.5} \operatorname{In}_{6} \mathrm{Gd}_{1.5} \mathrm{Ga}_{6} \mathrm{Si}_{3}\right)$. This result for $\Delta T_{A d}$ has the same order of magnitude as many of these other results for other $\mathrm{Ni}_{2} \mathrm{Mn}_{1+x} X_{1-x}$-type Heusler alloys shown in Table III.

Viable material candidates for magnetic refrigeration applications should have large $\Delta T_{A d}$ values in the temperature range of operation for the device (i.e., near room temperature). Many of the alloys with $\Delta T_{A d}$ values summarized in Table III exhibit magnetocaloric effects at temperatures below the typical operating temperatures of most magnetic refrigeration devices. The alloys characterized in this study have magnetocaloric effects that have been deliberately tuned to near room temperature. In particular, we observed $\Delta T_{A d} \sim-3 \mathrm{~K}$ near $310 \mathrm{~K}$ in alloy 5 (see Fig. 7). This sizeable $\Delta T_{A d}$ value near room temperature suggests that alloy 5 may be a good candidate material for magnetic refrigeration applications. As the search for optimized magnetocaloric properties in $\mathrm{Ni}_{2} \mathrm{Mn}_{1+x} \mathrm{X}_{1-x}$ Heusler alloys continues, our results suggest that enhanced properties can be obtained by limiting chemical disorder on the $X$-site and by alloying in small amounts of Gd.

\section{ACKNOWLEDGMENTS}

Measurements of magnetization and heat capacity were performed with support from the Department of Energy (DOE) under
Grant No. DE-FG02-04-ER46105. B.D.W. acknowledges support from the Central Washington University COTS Faculty Early Career Grant to perform data analysis and prepare this manuscript. $\mathrm{K}$. Sasmal is gratefully acknowledged for assistance in organizing references.

\section{REFERENCES}

${ }^{1}$ V. Franco, J. S. Blázquez, B. Ingale, and A. Conde, "The magnetocaloric effect and magnetic refrigeration near room temperature: Materials and models," Ann. Rev. Mater. Res. 42, 305 (2012).

${ }^{2}$ V. Franco, J. S. Blázquez, J. J. Ipus, J. Y. Law, L. M. Moreno-Ramírez, and A. Conde, "Magnetocaloric effect: From materials research to refrigeration devices," Prog. Mater. Sci. 93, 112 (2018).

${ }^{3}$ S. Fähler, U. K. Roßler, O. Kastner, J. Eckert, G. Eggeler, H. Emmerich, P. Entel, S. Müller, E. Quandt, and K. Albe, "Caloric effects in ferroic materials: New concepts for cooling,” Adv. Eng. Mater. 14, 10 (2012).

${ }^{4}$ K. A. Gschneidner, Jr., Y. Mudryk, and V. K. Pecharsky, "On the nature of the magnetocaloric effect of the first-order magnetostructural transition," Scr. Mater. 67, 572 (2012).

${ }^{\mathbf{5}}$ E. Brück, "Developments in magnetocaloric refrigeration," J. Phys. D: Appl. Phys. 38, R381 (2005).

${ }^{6}$ V. K. Pecharsky and K. A. Gschneidner, Jr., "Giant magnetocaloric effect in $\mathrm{Gd}_{5}\left(\mathrm{Si}_{2} \mathrm{Ge}_{2}\right)$," Phys. Rev. Lett. 78, 4494 (1997).

${ }^{7}$ V. K. Pecharsky, A. P. Holm, K. A. Gschneidner, Jr., and R. Rink, "Massive magnetic-field-induced structural transformation in $\mathrm{Gd}_{5} \mathrm{Ge}_{4}$ and the nature of the giant magnetocaloric effect," Phys. Rev. Lett. 91, 197204 (2003).

${ }^{8}$ A. de Campos, D. L. Rocco, A. M. G. Carvalho, L. Caron, A. A. Coelho, S. Gama, L. M. da Silva, F. C. G. Gandra, A. O. dos Santos, L. P. Cardoso, P. J. von Ranke, and N. A. de Oliveira, "Ambient pressure colossal magnetocaloric effect tuned by composition in $\mathrm{Mn}_{1-x} \mathrm{Fe}_{x} \mathrm{As}$," Nat. Mater. 5, 802 (2006).

${ }^{9}$ V. K. Pecharsky and K. A. Gschneidner, "Tunable magnetic regenerator alloys with a giant magnetocaloric effect for magnetic refrigeration from $\sim 20$ to 290 K," Appl. Phys. Lett. 70, 3299 (1997).

${ }^{10}$ D. H. Ryan, M. Elouneg-Jamróz, J. van Lierop, Z. Altounian, and H. B. Wang, "Field and temperature induced magnetic transition in $\mathrm{Gd}_{5} \mathrm{Sn}_{4}$ : A giant magnetocaloric material," Phys. Rev. Lett. 90, 117202 (2003).

${ }^{11}$ K. A. Gschneidner, Jr., V. K. Pecharsky, and A. O. Tsokol, "Recent developments in magnetocaloric materials," Rep. Prog. Phys. 68, 1479 (2005).

${ }^{12}$ D. Haskel, Y. B. Lee, B. N. Harmon, Z. Islam, J. C. Lang, G. Srajer, Y. Mudryk, K. A. Gschneidner, Jr., and V. K. Pecharsky, "Role of Ge in bridging ferromagnetism in the giant magnetocaloric $\mathrm{Gd}_{5}\left(\mathrm{Ge}_{1-x} \mathrm{Si}_{x}\right)_{4}$ alloys," Phys. Rev. Lett. 98, 247205 (2007).

${ }^{13}$ P. Nordblad, "Magnetocaloric materials: Strained relations," Nat. Mater. 12, 11 (2013).

${ }^{14}$ S. Gama, A. A. Coelho, A. de Campos, A. M. G. Carvalho, F. C. G. Gandra, P. J. von Ranke, and N. A. de Oliveira, "Pressure-induced colossal magnetocaloric effect in MnAs," Phys. Rev. Lett. 93, 237202 (2004).

${ }^{15}$ J. Liu, T. Gottschall, K. P. Skokov, J. D. Moore, and O. Gutfleisch, "Giant magnetocaloric effect driven by structural transitions," Nat. Mater. 11, 620 (2012).

${ }^{16}$ A. Planes, E. Stern-Taulats, T. Castán, E. Vives, L. Mañosa, and A. Saxena, "Caloric and multicaloric effects in shape memory alloys," Mater. Today: Proc. 2S, S477-S484 (2015).

${ }^{17}$ T. Bachaga, J. Zhang, M. Khitouni, and J. J. Sunol, "NiMn-based Heusler magnetic shape memory alloys: A review," Int. J. Adv. Manuf. Tech. 103, 2761-2772 (2019).

${ }^{18} \mathrm{M}$. Khan, N. Ali, and S. Stadler, "Inverse magnetocaloric effect in ferromagnetic $\mathrm{Ni}_{50} \mathrm{Mn}_{37+x} \mathrm{Sb}_{13-x}$ Heusler alloys,” J. Appl. Phys. 101, 053919 (2007).

${ }^{19}$ A. K. Nayak, K. G. Suresh, and A. K. Nigam, "Giant inverse magnetocaloric effect near room temperature in Co substituted NiMnSb Heusler alloys," J. Phys. D: Appl. Phys. 42, 035009 (2009). 
${ }^{20}$ Z. H. Liu, S. Aksoy, and M. Acet, "Influence of Sb on the magnetic and magnetocaloric properties of ferromagnetic shape memory alloy NiMnIn," J. Appl. Phys. 105, 033913 (2009).

${ }^{21}$ T. Krenke, E. Duman, M. Acet, E. F. Wassermann, X. Moya, L. Mañosa, and A. Planes, "Inverse magnetocaloric effect in ferromagnetic Ni-Mn-Sn alloys," Nat. Mater. 4, 450 (2005).

${ }^{22}$ R. Y. Umetsu, K. Ito, W. Ito, K. Koyama, T. Kanomata, K. Ishida, and R. Kainuma, "Kinetic arrest behavior in Martensitic transformation of NiCoMnSn metamagnetic shape memory alloy," J. Alloys Compd. 509, 1389 (2011).

${ }^{23}$ F. Chen, Y. X. Tong, X. L. Lu, B. Tian, L. Li, and Y. F. Zheng, "Martensitic transformation and shape memory effect of $\mathrm{NiCoMnSn}$ high temperature shape memory alloy," J. Mater. Eng. Perform. 21, 2509 (2012).

${ }^{\mathbf{2 4}}$ S. Dwevedi and B. Tiwari, "Martensitic transformations and magnetocaloric effect in Sn-doped NiMnIn shape memory alloy," J. Alloys Compd. 540, 16 (2012).

${ }^{25}$ I. Titov, M. Acet, M. Farle, D. González-Alonso, L. Mañosa, A. Planes, and T. Krenke, "Hysteresis effects in the inverse magnetocaloric effect in martensitic Ni-Mn-In and Ni-Mn-Sn,” J. Appl. Phys. 112, 073914 (2012).

${ }^{26} \mathrm{~A}$. Ghosh and K. Mandal, "Large magnetoresistance associated with large inverse magnetocaloric effect in Ni-Co-Mn-Sn alloys," Eur. Phys. J. B 86, 378 (2013).

${ }^{\mathbf{2 7}} \mathrm{A}$. Ghosh and K. Mandal, "Large inverse magnetocaloric effect in $\mathrm{Ni}_{48.5-x} \mathrm{Co}_{x} \mathrm{Mn}_{37} \mathrm{Sn}_{14.5}(x=0,1$ and 2$)$ with negligible hysteresis," J. Alloys Compd. 579, 295 (2013).

${ }^{28}$ D. Y. Cong, L. Huang, V. Hardy, D. Bourgault, X. M. Sun, Z. H. Nie, M. G. Wang, Y. Ren, P. Entel, and Y. D. Wang, "Low-field-actuated giant magnetocaloric effect and excellent mechanical properties in a NiMn-based multiferroic alloy," Acta Mater. 146, 142 (2018).

${ }^{29}$ X. Zhang, H. Zhang, M. Qian, and L. Geng, "Enhanced magnetocaloric effect in Ni-Mn-Sn-Co alloys with two successive magnetostructural transformations," Sci. Rep. 8, 8235 (2018)

${ }^{30}$ G. Cavazzini, F. Cugini, M. E. Gruner, C. Bennati, L. Righi, S. Fabbrici, F. Albertini, and M. Solzi, "Tuning the magnetic and magnetocaloric properties of austenitic Ni-Mn-(In,Sn) Heuslers," Scr. Mater. 170, 48-51 (2019).

${ }^{31}$ X. Zhao, J. Wen, Y. Gong, S. Ma, Q. Hu, and D. Wang, "Nonvolatile manipulation of the magnetocaloric effect in $\mathrm{Ni}_{43} \mathrm{Co}_{7} \mathrm{Mn}_{39} \mathrm{Sn}_{11} /(011)$ PMN-PT composite by electric fields," Scr. Mater. 167, 41-45 (2019).

${ }^{32}$ A. K. Pathak, I. Dubenko, J. C. Mabon, S. Stadler, and N. Ali, "The effect of partial substitution of In by $x=\mathrm{Si}, \mathrm{Ge}$ and $\mathrm{Al}$ on the crystal structure, magnetic properties and resistivity of $\mathrm{Ni}_{50} \mathrm{Mn}_{35} \mathrm{In}_{15}$ Heusler alloys," J. Phys. D: Appl. Phys 42, 045004 (2009).

${ }^{33}$ V. K. Sharma, M. K. Chattopadhyay, A. Khandelwal, and S. B. Roy, "Martensitic transition near room temperature and the temperature- and magnetic-field-induced multifunctional properties of $\mathrm{Ni}_{49} \mathrm{CuMn}_{34} \mathrm{In}_{16}$ alloy," Phys. Rev. B 82, 172411 (2010).

${ }^{34}$ L. Mañosa, D. González-Alonso, A. Planes, E. Bonnot, M. Barrio, J.-L. Tamarit, S. Aksoy, and M. Acet, "Giant solid-state barocaloric effect in the Ni-Mn-In magnetic shape-memory alloy,” Nat. Mater. 9, 478 (2010).

${ }^{35}$ V. K. Sharma, M. K. Chattopadhyay, L. S. Sharath Chandra, and S. B. Roy, "Elevating the temperature regime of the large magnetocaloric effect in a Ni-Mn-In alloy towards room temperature," J. Phys. D: Appl. Phys. 44, 145002 (2011).

${ }^{36} \mathrm{M}$. Ghahremani, H. ElBidweihy, L. H. Bennett, E. Della Torre, M. Zou, and F. Johnson, "Implicit measurement of the latent heat in a magnetocaloric NiMnIn Heusler alloy,” J. Appl. Phys. 113, 17A943 (2013).

${ }^{37}$ R. R. Fayzullin, A. V. Mashirov, V. D. Buchelnikov, V. V. Koledov, V. G. Shavrov, S. V. Taskaev, and M. V. Zhukov, "Direct and inverse magnetocaloric effect in $\mathrm{Ni}_{1.81} \mathrm{Mn}_{1.64} \mathrm{In}_{0.55}, \mathrm{Ni}_{1.73} \mathrm{Mn}_{1.80} \mathrm{In}_{0.47}$, and $\mathrm{Ni}_{1.72} \mathrm{Mn}_{1.51} \mathrm{In}_{0.49} \mathrm{Co}_{0.28}$ Heusler alloys," J. Commun. Technol. Electron. 61, 1129-1138 (2016).

${ }^{38}$ M. G. Zavareh, C. S. Mejia, A. K. Nayak, Y. Skourski, J. Wosnitza, C. Felser, and M. Nicklas, "Direct measurements of the magnetocaloric effect in pulsed magnetic fields: The example of the Heusler alloy $\mathrm{Ni}_{50} \mathrm{Mn}_{35} \mathrm{In}_{15}$," Appl. Phys. Lett. 106, 071904 (2015).
${ }^{39}$ T. Gottschall, K. P. Skokov, R. Burriel, and O. Gutfleisch, "On the $S(T)$ diagram of magnetocaloric materials with first-order transition: Kinetic and cyclic effects of Heusler alloys," Acta Mater. 107, 1-8 (2016).

${ }^{40}$ Z. Li, Z. Li, B. Yang, X. Zhao, and L. Zuo, "Giant low-field magnetocaloric effect in a textured $\mathrm{Ni}_{45.3} \mathrm{Co}_{5.1} \mathrm{Mn}_{36.1} \mathrm{In}_{13.5}$ alloy," Scr. Mater. 151, 61 (2018).

${ }^{41}$ B. Dahal, C. Huber, W. Zhang, S. Valloppilly, Y. Huh, P. Kharel, and D. Sellmyer, "Effect of partial substitution of In with Mn on the structural, magnetic, and magnetocaloric properties of $\mathrm{Ni}_{2} \mathrm{Mn}_{1+x} \mathrm{In}_{1-x}$ Heusler alloys," J. Phys. D: Appl. Phys. 52, 425305 (2019).

${ }^{42}$ P. Devi, C. S. Mejia, M. G. Zavareh, K. K. Dubey, P. Kushwaha, Y. Skourski, C. Felser, M. Nicklas, and S. Singh, "Improved magnetostructural and magnetocaloric reversibility in magnetic Ni-Mn-In shape-memory Heusler alloy by optimizing the geometric compatibility condition," Phys. Rev. Mater. 3, 062401 (2019).

${ }^{43}$ X.-M. Huang, L.-D. Wang, H.-X. Liu, H.-L. Yan, N. Jia, B. Yang, Z.-B. Li, Y.-D. Zhang, C. Esling, X. Zhao, and L. Zuo, "Correlation between microstructure and martensitic transformation, mechanical properties and elastocaloric effect in Ni-Mn-based alloys," Intermetallics 113, 106579 (2019).

${ }^{44}$ D. M. Nicholson, K. Odbadrakh, A. Rusanu, M. Eisenbach, G. Brown, and B. M. Evans III, First principles approach to the magnetocaloric effect: Application to $\mathrm{Ni}_{2} \mathrm{MnGa}$," J. Appl. Phys. 109, 07A942 (2011)

${ }^{45}$ Z. H. Liu, M. Zhang, W. Q. Wang, W. H. Wang, J. L. Chen, G. H. Wu, F. B. Meng, H. Y. Liu, B. D. Liu, J. P. Qu, and Y. X. Li, "Magnetic properties and martensitic transformation in quaternary Heusler alloy of NiMnFeGa," J. Appl. Phys. 92, 5006 (2002).

${ }^{46}$ J. Marcos, L. Mañosa, A. Planes, F. Casanova, X. Batlle, and A. Labarta, "Multiscale origin of the magnetocaloric effect in Ni-Mn-Ga shape-memory alloys," Phys. Rev. B 68, 094401 (2003).

${ }^{47}$ P.-P. Li, J.-M. Wang, and C.-B. Jiang, "Martensitic transformation in Cu-doped NiMnGa magnetic shape memory alloys," Chin. Phys. B 20, 028104 (2011).

${ }^{48}$ S. Y. Yu, S. S. Yan, S. S. Kang, X. D. Tang, J. F. Qian, J. L. Chen, and G. H. Wu, "Magnetic field-induced martensite-austenite transformation in Fe-substituted NiMnGa ribbons," Scr. Mater. 65, 9 (2011).

${ }^{49}$ C. Huang, Y. Wang, H. Wu, X. Liao, S. Yang, S. Wei, J. Wang, and X. Song, "Fe substitution induced intermartensitic transition and its internal stress dependent transforming behavior in Ni-Mn-Ga based alloy," J. Alloys. Compd. 581, 812 (2013)

${ }^{50}$ R. Fayzullin, V. D. Buchelnikov, S. Taskaev, M. Drobosyuk, and V. V. Khovaylo, "Experimental study of magnetocaloric effect in Ni-Fe-Mn-Ga and Ni-Co-Mn-Ga Heusler alloys," Mater. Sci. Forum 738-739, 456 (2013).

${ }^{51} \mathrm{~B}$. Wang and Y. Liu, "Exchange bias and inverse magnetocaloric effect in Co and $\mathrm{Mn}$ co-doped $\mathrm{Ni}_{2} \mathrm{MnGa}$ shape memory alloy," Metals 3, 69 (2013).

${ }^{52}$ R. I. Barabash, O. M. Barabash, D. Popov, G. Shen, C. Park, and W. Yang, "Multiscale twin hierarchy in NiMnGa shape memory alloys with $\mathrm{Fe}$ and $\mathrm{Cu}$," Acta Mater. 87, 344 (2015).

${ }^{53}$ J. Liu, Y. Gong, Y. You, X. You, B. Huang, X. Miao, G. Xu, F. Xu, and E. Brück, "Giant reversible magnetocaloric effect in MnNiGe-based materials: Minimizing thermal hysteresis via crystallographic compatibility modulation," Acta Mater. 174, 450-458 (2019).

${ }^{54} \mathrm{~T}$. Gottschall, K. P. Skokov, B. Frincu, and O. Gutfleisch, "Large reversible magnetocaloric effect in Ni-Mn-In-Co," Appl. Phys. Lett. 106, 021901 (2015)

${ }^{55}$ J. I. Pérez-Landazábal, V. Recarte, V. Sánchez-Alarcos, M. Jiménez Ruiz, and E. Cesari, "Outstanding role of the magnetic entropy in arrested austenite in an ordered $\mathrm{Ni}_{45} \mathrm{Mn}_{36.7} \mathrm{In}_{13.3} \mathrm{Co}_{5}$ metamagnetic shape memory alloy," Scr. Mater. 168, 91-95 (2019).

${ }^{56}$ S. K. Sarkar, Sarita, P. D. Babu, A. Biswas, V. Siruguri, and M. Krishnan, "Giant magnetocaloric effect from reverse martensitic transformation in Ni-Mn-Ga-Cu ferromagnetic shape memory alloys," J. Alloys Compd. 670, 281 (2016).

${ }^{57}$ R. Barabash, E. Vineyard, T. R. Watkins, W. Porter, and O. Barabash, "High entropy NiMn-based magnetic refrigerant materials," U.S. patent 20,160,025,386 A1 (2016). 
${ }^{58}$ J. C. Lashley, M. F. Hundley, A. Migliori, J. L. Sarrao, P. G. Pagliuso, T. W. Darling, M. Jaime, J. C. Cooley, W. L. Hults, L. Morales, D. J. Thoma, J. L. Smith, J. Boerio-Goates, B. F. Woodfield, G. R. Stewart, R. A. Fisher, and N. E. Phillips, "Critical examination of heat capacity measurements made on a quantum design physical property measurement system," Cryogenics 43, 369 (2003). ${ }^{\mathbf{5 9}} \mathrm{G}$. A. Slack, "Platinum as a thermal conductivity standard," J. Appl. Phys. 35, 339 (1964).

${ }^{60}$ J. Sharma, A. A. Coelho, D. V. M. Repaka, R. V. Ramanujan, and K. G. Suresh, "Pressure induced martensitic transition, magnetocaloric and magneto-transport properties in Mn-Ni-Sn Heusler alloy," J. Magn. Mag. Mater. 487, 165307 (2019).
${ }^{61}$ M. Pasquale, C. P. Sasso, L. H. Lewis, L. Giudici, T. Lograsso, and D. Schlagel, "Magnetostructural transition and magnetocaloric effect in $\mathrm{Ni}_{55} \mathrm{Mn}_{20} \mathrm{Ga}_{25}$ single crystals," Phys. Rev. B 72, 094435 (2005).

${ }^{62}$ S. A. Nikitin, G. Myalikgulyev, A. M. Tishin, M. P. Annaorazov, K. A. Asatryan, and A. L. Tyurin, "The magnetocaloric effect in $\mathrm{Fe}_{49} \mathrm{Rh}_{51}$ compound," Phys. Lett. A 148, 363 (1990).

${ }^{63}$ O. Tegus, E. Brück, L. Zhang, X. Dagula, K. H. J. Buschow, and F. R. de Boer, "Magnetic-phase transitions and magnetocaloric effects," Physica B 319, 174 (2002).

${ }^{64} \mathrm{Y}$. Q. Zhang and Z. D. Zhang, "Giant magnetoresistance and magnetocaloric effects of the $\mathrm{Mn}_{1.82} \mathrm{~V}_{0.18} \mathrm{Sb}$ compound," J. Alloys Compd. 365, 35 (2004). 